\title{
Comment on 'Anav et al. (2016) Comparing concentration-based (AOT40) and stomatal uptake (PODY) metrics for ozone risk assessment to European forests' Global Change Biology, 22(4), 1608-1627, doi:10.1111/gcb.13138
}

\author{
DAVID SIMPSON ${ }^{1,2}$ \\ ${ }^{1}$ EMEP MSC-W, Norwegian Meteorological Institute, Oslo, Norway, ${ }^{2}$ Department Earth E Space Sciences, Chalmers University \\ of Technology, Gothenburg, Sweden
}

The recent paper by Anav et al. (2016) (hereafter A2016) claims to make new and improved calculations of two metrics associated with ozone damage to vegetation: AOT40 (accumulated ozone over a threshold of $40 \mathrm{ppb}$ ) and PODY (phytotoxic ozone dose over a flux threshold of Y). A2016 claim to improve upon previously used methods of the EMEP MSC-W model (Simpson et al., 2007, 2012 - hereafter S2012), but both misrepresents the EMEP model and, unfortunately, applies an incorrect equation to the calculation of PODY.

With regard to the EMEP model, A2016 suggest that the exclusion of soil water (SW) effects in the published maps (at www.emep.int) of PODY and AOT40 from the EMEP model is a weakness of the model. However, SW effects have been tested in the EMEP model since the late 1990s (Simpson et al., 2003), and included operationally around 2010 (S2012). Inclusion or exclusion depends on the usage. The EMEP maps shown by A2016 excluded SW because they are designed to show the potential for ozone damage to well-watered sensitive vegetation - following the parameterization of generic species intended for integrated assessment modelling (IAM) by the LRTAP Convention's ICP Vegetation (http://icpvegetation.ceh.ac.uk/, LRTAP 2015). Further, A2016 claim that EMEP uses a 'simple' method for SW, but this is misleading. EMEP uses the soil moisture index (SMI) provided by the state-of-theart ECMWF model (www.ecmwf.int). SMI is designed to be robust in the face of the variations in, and lack of reliable data on, soil characteristics - this recognizes that no model (including A2016's) can accurately predict SW across large areas (e.g. Wipfler et al., 2011).

A2016 further claim that EMEP models only two generic forest types. Actually, S2012 lists 10 categories of standard vegetation (incl. four forest types) for which ozone fluxes are calculated, plus three 'generic'

Correspondence: David Simpson, tel. +46 31772 1588, fax +46 31 772 1884, e-mail: david.simpson@chalmers.se categories (incl. two forest) for IAM. In Mills et al.'s study (Mills et al., 2011b), clover was addressed, and additional categories have been modelled in ad hoc studies for ICP Vegetation.

With regard to the approach of A2016, the equation presented for PODY (Eqn 7) is incorrect, and not in accord with LRTAP (2015). A2016 calculated stomatal flux as simply the product of stomatal conductance $\left(\mathrm{g}_{\mathrm{s}}\right)$ and ozone concentration, ignoring aerodynamic effects and nonstomatal sinks. The importance of nonstomatal sinks has been stressed many times (e.g. Simpson et al., 2003; Tuovinen et al., 2004, 2009), so this omission was surprising. The correct equation should be:

$$
\text { Fst }=g_{b} \cdot g_{s} /\left(g_{b}+g_{s}+g_{\text {ext }}\right) \cdot\left[\mathrm{O}_{3}\right]
$$

where $g_{b}, g_{s}$ and $g_{e x t}$ are the leaf-level boundary layer, stomatal and external surface conductance respectively, and $\left[\mathrm{O}_{3}\right]$ is the ozone concentration estimated for the top of the canopy (Tuovinen et al., 2009; LRTAP, 2015).

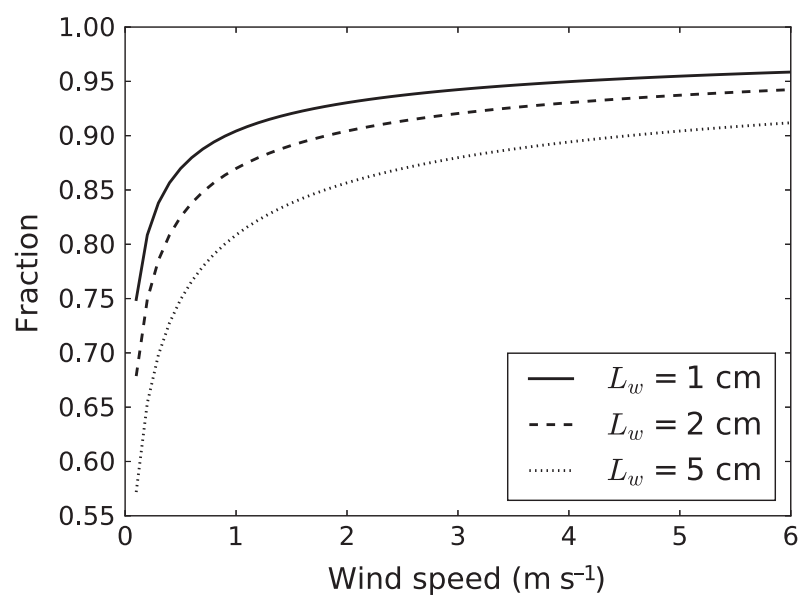

Fig. 1 Stomatal flux (Fst) calculated with Eqn (1) as a fraction of the value of Fst calculated by the A2016 approach (which ignores nonstomatal fluxes). Calculations using LRTAP (2015) approach, $\mathrm{g}_{\mathrm{s}}=0.5 \mathrm{~cm} \mathrm{~s}^{-1}$, for different leaf dimensions $\left(\mathrm{L}_{w}\right)$. 


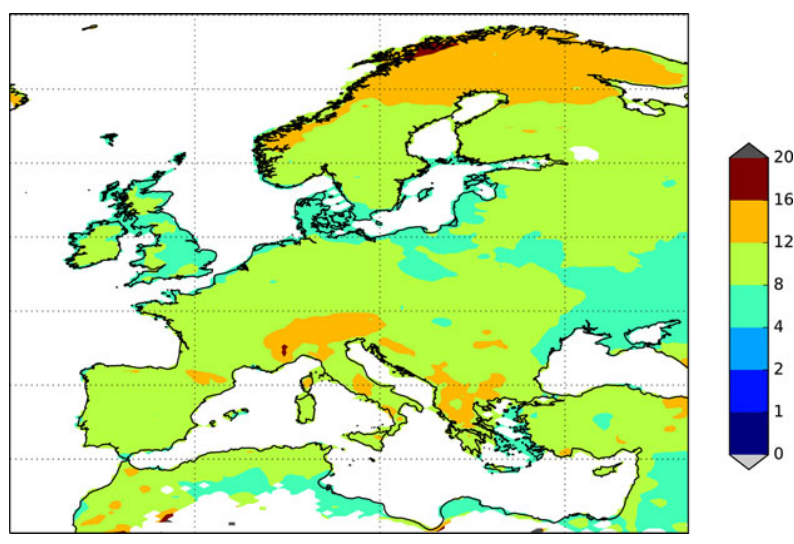

Fig. 2 Percentage error in estimated POD1 values if using the A2016 formulation for Fst instead of the correct Eqn (1) formulation. Example calculations with EMEP MSC-W model for year 2007.

Fst as calculated with Eqn (1) is always lower than with the equation of A2016, sometimes considerably so (Fig. 1). Errors in POD1 calculations are typically of order $10 \%$ but can approach $20 \%$ in some regions (Fig. 2); they would be higher for a higher flux threshold Y.

Eqn (5) of A2016 is also incorrect for the $f_{\mathrm{VPD}}$ term, but this looks like a typo and is not commented further.

This paper claims to provide better estimates of AOT40 and PODY, but the annual mean or all-station average $\mathrm{O}_{3}$ values presented are not good indicators of model performance for AOT40 or PODY. For the EMEP model, we have numerous comparisons against daily ozone data (see www.emep.int for evaluation reports), stomatal and canopy conductance (see Tuovinen et al., 2004, 2009; S2012, and refs therein) and even PODY values (Klingberg et al., 2008).

Other suggestions in A2016 are also questionable, for example that AOT40 should be calculated over all hours where $g_{s}>0$. It is well established that for many species, $g_{s}$ is low but nonzero at night. Application of the ideas of A2016 could significantly increase AOT40 values (especially for sites with typically high nighttime $\mathrm{O}_{3}$, e.g. mountain or coastal sites). Any redefinitions of this metric would also entail reconsideration of all dose-response data relationships to date.
A2016 suggest that AOT40 was chosen for its linear relationship with yield or biomass; this is misleading. Linear relationships are only applicable to well-watered experimental conditions, not to ambient conditions. This is one reason why LRTAP has moved towards the PODY approach (Mills et al., 2011a).

The concepts underpinning stomatal flux modelling in Europe have been driven by ICP Vegetation and involved numerous scientists from many different countries. A2016 miss much of the key literature associated with this work, suggesting a lack of appreciation for the discussions and difficulties behind the PODY concept and its practical application. Finally, it is a shame that the authors did not consult MSC-W before publicly presenting and wrongfully interpreting EMEP maps of ozone metrics. We could have corrected the misunderstandings and helped correct other features of A2016.

\section{References}

Anav A, De Marco A, Proietti C et al. (2016) Comparing concentration-based (AOT40) and stomatal uptake (PODY) metrics for ozone risk assessment to European forests. Global Change Biology, 22, 1608-1627.

Klingberg J, Danielsson H, Simpson D, Pleijel H (2008) Comparison of modelled and measured ozone concentrations and meteorology for a site in south-west Sweden implications for ozone uptake calculations. Environmental Pollution, 115, 99-111.

LRTAP (2015) Chapter 3 (Mills G et al.) of the LRTAP Convention Manual of Methodologies for Modelling and Mapping Effects of Air Pollution. Available at: http:// icpvegetation.ceh.ac.uk/ (accessed 18 July 2016).

Mills G, Pleijel H, Braun S et al. (2011a) New stomatal flux-based critical levels for ozone effects on vegetation. Atmospheric Environment, 45, 5064-5068.

Mills G, Hayes F, Simpson D, Emberson L, Norris D, Harmens H, Büker P (2011b) Evidence of widespread effects of ozone on crops and (semi-) natural vegetation in Europe (1990-2006) in relation to AOT40- and flux-based risk maps. Global Change Biology, 17, 592-613.

Simpson D, Tuovinen J-P, Emberson L, Ashmore M (2003) Characteristics of an ozone deposition module II: sensitivity analysis Water. Air and Soil Pollution, 143, 123-137.

Simpson D, Emberson L, Ashmore M, Tuovinen J-P (2007) A comparison of two different approaches for mapping potential ozone damage to vegetation. A model study. Environmental Pollution, 146, 715-725.

Simpson D, Benedictow A, Berge H et al. (2012) The EMEP MSC-W chemical transport model - technical description. Atmospheric Chemistry and Physics, 12, 7825-7865.

Tuovinen J-P, Ashmore M, Emberson L, Simpson D (2004) Testing and improving the EMEP ozone deposition module. Atmospheric Environment, 38, 2373-2385.

Tuovinen J-P, Emberson L, Simpson D (2009) Modelling ozone fluxes to forests for risk assessment: status and prospects. Annals of Forest Science, 66, 401.

Wipfler EL, Metselaar K, van Dam JC et al. (2011) Seasonal evaluation of the land surface scheme HTESSEL against remote sensing derived energy fluxes of the Transdanubian region in Hungary. Hydrology and Earth System Sciences, 15, 1257-1271. 